\title{
Violencia contra las mujeres en Oaxaca
}

\author{
Nallely Guadalupe Tello Méndez ${ }^{1}$ \\ Consorcio para el Diálogo Parlamentario y la Equidad Oaxaca AC²
}

Palabras clave: Género, violencia contra las mujeres, feminicidio
En este artículo se explica brevemente qué es la violencia contra las mujeres, presenta datos estadísticos sobre la misma y, en particular, sobre el feminicidio -el asesinato de las mujeres por razones de género- que es una grave problemática que va en aumento en Oaxaca. Al final, se proponen algunas acciones que pueden realizarse con la finalidad de evitar que la violencia contra las mujeres siga incrementándose.

\section{¿Qué es la violencia contra las mujeres?}

La violencia contra las mujeres es el maltrato físico, psicológico, emocional, espiritual, sexual, económico, patrimonial e institucional que se realiza contra las mujeres por considerarlas inferiores a los hombres. De lo anterior, podrás darte cuenta que se presenta de distintas formas y se da en diferentes espacios (casa, escuela, calle, trabajo, etcétera). A veces se piensa que sólo los golpes son la única forma de ejercer violencia, pero esto no es así. En general, la violencia puede ir escalando, es decir, pasa de frases como "¿eres tonta o qué?" o "¿estás gorda y aun asi te pones eso?", hasta prohibiciones para salir con tus amistades, jaloneos, forcejeos, golpes e incluso, el feminicidio que es el asesinato de las mujeres por el hecho de pertenecer a este género y por-

1 Maestra en Sociología por el Instituto de Investigaciones Sociológicas de la Universidad Autónoma Benito Juárez de Oaxaca y especialista en Gestión Educativa por la Facultad Latinoamericana de Ciencias Sociales (FLACSO Argentina). Integrante de Consorcio para el Diálogo Parlamentario y la Equidad Oaxaca AC. consorciooaxaca.nallely@gmail.com

2 Pensamientos No. 104, Col. Reforma, Oaxaca de Juárez, Oaxaca. Teléfono (01 951) 1328996 
que las personas que las matan las consideran de su propiedad y piensan que pueden hacer lo que sea con ellas, incluyendo el hecho de asesinarlas.

\section{Violencia en las relaciones de pareja}

Como la violencia muchas veces escala, es importante que podamos ponerle un alto desde sus primeras manifestaciones. Cuando somos jóvenes y estamos enamoradas, no deseamos vivenciar la pérdida de la persona que queremos. No obstante, es importante saber que él o ella no va a cambiar por ti, que el amor no lo puede todo, que no te maltrata porque te ama, sino porque quiere controlarte. Todas estas son expresiones de la violencia, que a la larga nos harán sufrir más permaneciendo en esa relación, que alejándonos de ella. De acuerdo con la Encuesta Nacional sobre la Dinámica de las Relaciones en los Hogares (ENDIREH, 2016, como se citó en Altamirano, 2017) en Oaxaca 46.1\% de las mujeres sufrió violencia en su última relación de pareja.

Sin embargo, no solamente en este tipo de relaciones podemos estar viviendo violencia. Oaxaca, de acuerdo con esa misma encuesta, ocupa el quinto lugar en el país en violencia escolar contra las mujeres. Ello significa que en las escuelas podemos ser víctimas de menosprecio, golpes, insultos, agresiones sexuales, entre otras.

\section{Feminicidios}

Como hemos dicho, la violencia contra las mujeres puede ir en aumento y su desenlace son los feminicidios. Según datos del INEGI, entre 2013 y 2015 , 6,488 mujeres fueron asesinadas en nuestro país. Lo que supone $46 \%$ más que en el periodo entre 2007 y 2009 (Barragán, 2016). El Observatorio Ciudadano Nacional de Feminicidio señaló que, de 2015 a 2017, el número de feminicidios ha crecido 74\% en México (Ansa Latina, 2018) ¿No te parece alarmante el incremento en el número de feminicidios en los años mencionados?

En Oaxaca, de acuerdo con el registro hemerográfico que realizamos en Consorcio Oaxaca, del 1 de diciembre de 2016 al 30 de junio de 2018 se registraron 191 feminicidios. Ante esto, es importante decir que los feminicidios no sólo han crecido en el número de víctimas, sino también en la crueldad en la que se manifiesta el desprecio por la vida de las mujeres ante la complicidad e ineptitud de las autoridades, que mantienen cifras de impunidad hasta en $99 \%$. 
A nivel nacional, 36\% de las mujeres fueron asesinadas en la vía pública, 34\% en la vivienda (Kánter, 2016). Estos datos nos ayudan a entender que muchos de los asesinos de las mujeres son sus conocidos y no personas extrañas. Por ello, nuevamente, es importante detener la violencia desde sus primeras expresiones.

Debemos tomar en cuenta que detrás de cada feminicidio hay una serie de relaciones de esa mujer con otras personas: amistades, familia, hijos, compañeras y compañeros de trabajo que se ven afectadas, es decir, el feminicidio no solo acaba con la vida de una mujer, sino que lastima profundamente el tejido comunitario a su alrededor. Por tanto, la violencia contra las mujeres no es un asunto que debamos resolver únicamente las mujeres, sino que es una problemática en la cual todas las personas tenemos que involucrarnos para evitar que siga sucediendo.

\section{¿Qué podemos hacer?}

Hay muchas cosas que podemos hacer para prevenir la violencia contra las mujeres y el feminicidio, aquí sugerimos algunas, pero en la medida en que conozcas más del tema podrás generar mayores opciones:

1. Es importante tener información sobre cómo identificar, prevenir y atender la violencia contra las mujeres, así que puedes buscar charlas, talleres, o hacer campañas de información en tu escuela, trabajo, colonia.

2. Si tienes una amiga que sufre violencia es importante que no la dejes sola. Muchas veces los agresores les hacen creer que no tienen a nadie y ellas se quedan en dichas relaciones, porque piensan que no cuentan con ningún apoyo que no sea el de sus parejas violentas.

3. Es frecuente que se juzgue a las victimas y no a los agresores, lo que se expresa en frases como "porque quiere está ahi" o "ella se lo buscó", le pasó lo que le pasó por cuzca". Estas son ideas que no ayudan a las mujeres a salir de los círculos de violencia porque se sienten señaladas y solas; cuando una persona ejerce violencia, el responsable es el agresor, no las víctimas.

4. No reproduzcas chistes machistas, parecen inofensivos pero precisamente por eso son peligrosos, porque ayudan a la construcción de un pensamiento dañino de una manera que parece divertido, pero que luego se puede convertir en actos de violencia contra las mujeres. 
5. La violencia contra las mujeres es un delito y, como tal, debe ser sancionado por las autoridades, así que denúncialo y exige que se garantice tu derecho a vivir una vida libre de violencia.

6. Recuerda que las y los familiares de las mujeres que son víctimas de feminicidio tienen derecho a la verdad y la justicia, participa en acciones para exigir que esto se garantice.

\section{Referencias}

Altamirano N. Oaxaca, quinto lugar en violencia escolar y también familiar, según ENDIREH 2016. (20 marzo de 2018). NVI. Noticias. Recuperado de: https://www.nvinoticias.com/nota/67713/oaxaca-quinto-lugar-en-violencia-escolar

ANSA LATINA. Agencia Italiana de Noticias. (29 marzo de 2018). Aumentan 74\% feminicidios en tres años. ANSA LATINA. Agencia Italiana de Noticias. Recuperado de: http://www.ansalatina.com/americalatina/noticia/mexico/2018/01/22/ aumentan-74-femicidios-en-tres-anos_ac33b129-67e5-473a-bcaa54b3102d48ec.html

Barragán A. (29 de marzo de 2018). Suben feminicidios en México: 6,488 mujeres asesinadas entre 2013 y 2015. El Economista. Recuperado de http://www. economiahoy.mx/nacional-eAm-mx/noticias/7406635/03/16/Siete-mujeresmueren-al-dia-en-Mexico-victimas-de-la-violencia.html

Hernández C, A.M, Liendro, E y Gamblin, S. (2011) jParemos la violencia contra las mujeres y las niñas! Guía para autoridades comunitarias: la atención a mujeres que viven violencia, Oaxaca: Consorcio para el Diálogo Parlamentario y la Equidad Oaxaca, A.C. Recuperado de https://docplayer.es/80082640-Consorcio-para-el-dialogo-parlamentario-y-la-equidad-oaxaca-a-c.html

Consorcio para el Diálogo Parlamentario y la Equidad Oaxaca AC, Feminicidios. Violencia Feminicida en Oaxaca (30 de junio de 2018), Recuperado de https://violenciafeminicida.consorciooaxaca.org. $\mathrm{mx} /$

Kánter C, I.d.R. (2016), Asesinatos de Mujeres en México, México: Senado de la República, LXIII Legislatura/Instituto Belisario Domínguez (Cuaderno de Investigación. Dirección General de Análisis Legislativo). Recuperado de https://violenciafeminicida.consorciooaxaca.org.mx/wp-content/uploads/sites/55/2017/08/asesinatos_mujeres_mexico.pdf 


\section{Conceptos básicos}

Acción afirmativa: Medida de carácter temporal encaminada a acelerar la igualdad de hecho entre mujeres y hombres, y corrige la distribución desigual histórica de oportunidades y beneficios entre mujeres y hombres (INMUJERES, 2007).

Androcentrismo: Es una visión de la realidad desde la perspectiva masculina, que consiste en considerar al ser humano de sexo masculino como el centro del universo, como el único observador válido de cuanto sucede en nuestro mundo y de dictar leyes, de imponer la justicia, de gobernar al mundo (Mujeres en red).

Brecha de desigualdad: Es una medida estadística que muestra la distancia entre mujeres y hombres respecto a un mismo indicador. Expresa la situación de discriminación que viven las mujeres por el hecho de ser mujeres, en todas las áreas del desempeño económico, social, cultural, sanitario, científico, educativo, político, etcétera.

Discriminación: Es toda distinción, exclusión, restricción, preferencia u omisión por motivos de sexo, raza, color, nacionalidad, orientación sexual, que restringe el goce o ejercicio de los derechos humanos, las libertades fundamentales y la igualdad de oportunidades de las personas.

División sexual del trabajo: Se refiere a la división del trabajo productivo y reproductivo. Se establece sobre la base de los roles diferenciados que se asignan a los hombres y a las mujeres en cada sociedad.

Equidad de género: Significa que se da un trato diferenciado a mujeres y hombres, con el fin de compensar el desequilibrio histórico y social que 
les impide a las mujeres participar activamente y de la misma manera que los hombres en el desarrollo de sus sociedades (Le Monde, 2006).

Estereotipos de género: Es una opinión o un prejuicio generalizado acerca de los atributos o las características que hombres y mujeres poseen o deberian poseer, o de las funciones sociales que ambos desempeñan o deberían desempeñar (OACNUDH).

Feminismo: Corriente de pensamiento en permanente evolución por la defensa de la igualdad de derechos y oportunidades entre ambos sexos. Constituye una forma diferente de entender el mundo, las relaciones de poder, las estructuras sociales y las relaciones entre los sexos (Mujeres en la Red).

Género: Conjunto de características sociales, culturales, políticas, psicológicas, jurídicas y económicas, que la sociedad les asigna a las personas de forma diferenciada como propias de hombres y mujeres. Los géneros son construcciones socioculturales que varian a través de la historia y se refieren a los rasgos psicológicos y culturales que la sociedad atribuye a lo que considera "masculino" o "femenino" mediante la educación, el uso del lenguaje, la familia, las instituciones o la religión (INMUJERES, 2007).

Igualdad de género: La igualdad entre mujeres y hombres se refiere a la eliminación de toda forma de discriminación que se genere por pertenecer a cualquier género (Ley General para la lgualdad entre Mujeres y Hombres).

Discriminación por sexo: Es la más extendida, ya que aproximadamente la mitad de la población mundial está conformada por mujeres y la otra mitad por varones. A la discriminación por sexo se le denomina sexismo.

Machismo: Conjunto de creencias, conductas, actitudes y prácticas sociales que justifican y promueven la discriminación hacia las mujeres (INMUJERES, 2007)

Misoginia: Significa temor y odio a las mujeres. Con ese término se hace referencia a cualquier forma, brutal o sutil, de inferiorización, ridiculización, exclusión, violencia y opresión a las mujeres como género y a cada una en particular (CONAPO, 2000).

Patriarcado: El término procede del griego y significa "gobierno de los padres". El adjetivo patriarcal describe una estructura en la que los varones tienen poder sobre las mujeres. Gerda Lerner (1986) define el patriarca- 
do como "la manifestación e institucionalización del dominio masculino sobre las mujeres y niños y niñas de la familia y la ampliación de ese dominio sobre las mujeres en la sociedad en general" (Barba, 2017).

Perspectiva de género: Herramienta teórico-metodológica de la teoría de género que permite visualizar y reconocer la existencia de relaciones de jerarquia y desigualdad entre hombres y mujeres, expresadas en forma de injusticia, subordinación y discriminación hacia las mujeres. Además, permite reconocer las causas que las producen y formular mecanismos para superar estas brechas, ya que ubica la problemática no en las mujeres o los hombres, sino en las relaciones socialmente construidas sobre el poder y la exclusión.

Roles de género: El papel (rol) de género se configura con el conjunto de normas y prescripciones que dictan la sociedad y la cultura sobre el comportamiento femenino o masculino. Aunque hay variantes de acuerdo con la cultura, la clase social, el grupo étnico y estrato generacional de las personas, se puede sostener una división básica que corresponde a la división sexual del trabajo más primitiva: las mujeres paren a los hijos y, por tanto, los cuidan: ergo, lo femenino es lo maternal, lo doméstico, contrapuesto con lo masculino, que se identifica con lo público (Lamas, 2002).

Sexismo: Desigualdad en la valoración de los géneros. Alude a toda distinción, exclusión o restricción que, basada en estereotipos y creencias de género, anulan el reconocimiento o el ejercicio de los derechos humanos de las mujeres. Se trata de una práctica con raíces culturales profundas y socialmente extendidas, cuya lógica de funcionamiento se halla en la expresión sistemática de menosprecio e invisibilización del papel de las mujeres, sus aportes y sus demandas.

Sexo: Conjunto de características físicas, biológicas, anatómicas y fisiológicas de los seres humanos, que los definen como hombre o mujer (INMUJERES, 2007).

Teoría de género: Abarca los planteamientos metodológicos, filosóficos, éticos, y políticos para comprender el complejo de relaciones de poder que determina la desigualdad entre hombres y mujeres. Utiliza las categorías sexo y género como herramienta central. Busca recoger la diversidad en los modos en que se presentan las relaciones de género al interior de las distintas sociedades y, a la vez, dar cuenta de la identidad genérica tanto de hombres como de mujeres. 
Trabajo productivo: Todas las tareas que se realizan en el ámbito de lo público. Estas tareas las desarrollan tradicionalmente los hombres, es decir, son tareas estereotipadamente masculinas. Es remunerado, visible, reconocido, genera derechos, prestaciones, riqueza y acceso a créditos.

Trabajo reproductivo o de cuidados: Todas las tareas que se realizan en el ámbito privado (doméstico). Estas tareas las desarrollan primordialmente las mujeres, es decir, son tareas estereotipadamente femeninas. Con las siguientes características: gratuito, subvalorado (se considera secundario), carece de prestigio y reconocimiento, no genera derechos, no genera prestaciones, es oculto socialmente.

Violencia de género: Todas las formas mediante las cuales se intentan perpetuar el sistema de jerarquías impuesto por la cultura patriarcal. Se trata de una violencia estructural que se dirige hacia las mujeres con el objeto de mantener o incrementar su subordinación al género masculino hegemónico.

\section{Referencias}

Barba, M. ¿Qué es el patriarcado? (30 marzo 2018). Recuperado de https://www. aboutespanol.com/que-es-el-patriarcado-1271580

CONAPO. Consejo Nacional de Población (2000) La perspectiva de género. Guía para diseñar, poner en marcha, dar seguimiento y evaluar proyectos de investigación y acciones públicas y civiles. México. Recuperado de https://www.ceiich.unam. $\mathrm{mx} /$ genero/conapo/genero.html

Serralde, S., y Ugalde, Y. (2007). Glosario de género. México: INMUJERES. Recuperado de http://cedoc.inmujeres.gob.mx/documentos_download/100904.pdf

Le Monde selon les femmes (2006). Cuestiones esenciales sobre Género. O1. Conceptos básicos. Madrid: ACSUR-Las Segovias. Recuperado de https://www.unirioja. es/igualdad/archivos/Cuestiones_de_Genero.pdf

S/a. (30 de marzo de 2018). ¿Qué es el feminismo? Mujeres en Red. Periódico feminista. Recuperado de http://www.mujeresenred.net/spip.php?article1308 